Research paper

\title{
Placing land cover pattern preferences on the map: Bridging methodological approaches of landscape preference surveys and spatial pattern analysis
}

\author{
Sónia Carvalho Ribeiro ${ }^{\mathrm{a}, *}$, Antonello Migliozzi $^{\mathrm{b}}$, Guido Incerti $^{\mathrm{b}}$, Teresa Pinto Correia ${ }^{\mathrm{a}, \mathrm{c}}$ \\ a ICAAM - Instituto de Ciências Agrárias e Ambientais Mediterrânicas, Universidade de Évora, Núcleo da Mitra, Ap. 94, 7002-554, Évora, Portugal \\ ${ }^{\mathrm{b}}$ Department of Agriculture, Laboratory of Applied Ecology - University of Napoli “Federico II", Via Università 100, 80055 Portici, Italy \\ ${ }^{c}$ DPAO - Departmento de Paisagem Ambiente e Ordenamento, Universidade de Évora, Núcleo da Mitra, Ap. 94, 7002-554, Évora, Portugal
}

\section{H I G H L I G H T S}

- This work fills a research gap by bridging landscape preference and spatial planning methodological approaches through the development of the Landscape Preferences Spatial Framework (LPSF).

- The Landscape Preferences Spatial Framework (LPSF) is innovative in translating local scale preferences into regional scale planning settings.

- The results show the ways in which preferences for land cover patterns can be associated with contrasting land uses.

- This method is particularly suited for the fuzzy landscape settings of the Mediterranean.

\section{A R T I C L E I N F O}

\section{Article history:}

Received 16 July 2012

Received in revised form 18 February 2013

Accepted 27 February 2013

\section{Keywords}

Landscape preferences

Spatial pattern analysis

Land cover preference mapping

Interdisciplinarity

Cluster analysis

Portugal

\begin{abstract}
A B S T R A C T
This paper presents an innovative methodological framework - Landscape Preferences Spatial Framework (LPSF) - which is able to translate landscape preferences, as expressed by various users, concerning possible land cover pattern compositions into land cover pattern preference maps. The innovative potential of the contribution lies in the exploration of a comprehensive methodical framework that facilitates the spatial representations of landscape demands by relevant user groups thus bridging the gap between landscape preference research and landscape planning. The LPSF developed here goes beyond the state of the art in translating local scale preference by people into regional scale planning settings. Throughout the paper the development and testing of the LPSF is described and explained. Although the paper focuses on the conceptual framework of the method, it also shows the results of its application in a case study.

(c) 2013 Elsevier B.V. All rights reserved.
\end{abstract}

\section{Introduction}

The study of the various "human dimensions" of landscapes has become increasingly prominent in recent years. This is not only because of the role that humans play in changing ecosystems worldwide. It is also a feature of shifting preferences for landscape patterns by a range of landscape users (Hunziker, Buchecker, \& Hartig, 2007). Yet, even in the face of a huge body of literature reporting preferences by people for specific landscape features (Buijs, Pedroli, \& Luginbu, 2006; Matsuoka \& Kaplan, 2008; Misgav, 2000; Ribe, 2002; Roovers, Hermy, \& Gullink, 2002), and an

\footnotetext{
* Corresponding author at: ICAAM - Instituto de Ciências Agrárias e Ambientais Mediterrânicas, Universidade de Évora, Núcleo da Mitra, Ap. 94, 7002-554, Portugal. Tel.: +351 $266740800 \times 4445$.

E-mail addresses: sribeiro@uevora.pt, sonia.carvalhoribeiro@googlemail.com (S. Carvalho Ribeiro), migliozz@cds.unina.it (A. Migliozzi), guido.incerti@unina.it (G. Incerti), mtpc@uevora.pt (T. Pinto Correia).
}

established research field on landscape spatial pattern analysis for informing landscape planning and management (Botequilha Leitao \& Ahern, 2002; Carvalho-Ribeiro \& Lovett, 2009; Gulinck, Múgica, de Lucio, \& Atauri, 2001; Gustafson, 1998; McGarigal, Cushman, Neel, \& Ene, 2002; Uuemaa, Antrop, Roosaare, Marja, \& Mander, 2009), reliably connecting landscape preferences to land cover patterns composition is still a missing dimension. One specific challenge is to express the multiple demands sought by people in a spatially explicit way so as faithfully to guide regional landscape planning and management.

This article is innovative in presenting an exploratory methodological framework that facilitates the spatial representation of landscape preferences of relevant user groups. This bridges landscape preference and spatial planning methodological approaches in an exploratory way. Therefore, the research summarized here develops an innovative methodological approach, thereafter named as Landscape Preferences Spatial Framework (LPSF), for translating landscape preferences for possible land cover pattern compositions into land cover patterns preference maps. 
In tackling this, the research had to address the conceptual difficulties of defining landscape preferences. Landscape "is an area, as perceived by people, whose character is the result of the action and interaction of natural and/or human factors" (ELC, 2000, article 1). In defining the term people, a distinction is made between the general public and specific landscape user groups (ELC, 2000; Rogge, Dessein, \& Gulinck, 2011; Sevenant \& Antrop, 2010). This is because individuals might have distinct landscape preferences according to whether they adopt a user/consumer or a citizen/public viewpoint (van Rensburg, Mill, Common, \& Lovett, 2002). There is robust empirical work which reveals that land cover preferences by user groups is highly functional (Buijs et al., 2006; Carvalho-Ribeiro \& Lovett, 2011; Carvalho-Ribeiro, Lovett, \& O'Riordan, 2010; PintoCorreia, Barroso, Menezes, \& Surova, 2011; Surova \& Pinto-Correia, 2008). Therefore, it is likely that depending on the usage (e.g. for farming, hunting or walking) a given individual might prefer different compositions and arrangements of individual land cover types (land cover patterns). Those land covers and its patterns are inherently associated with physical landscape attributes such as terrain, water, climate or geology. Whilst we fully appreciate that these attributes are drivers of land cover types and hence of associated patterns, for simplification, we kept those unchangeable (e.g. similar terrain configuration) testing only user group's preferences for land cover pattern compositions. We acknowledge that although land cover and land use are often used as landscape indicators, they actually represent only one (or at most a few) of the visible landscape "layers". Despite the awareness that the use of land cover in landscape preferences studies both reduces and simplifies the landscape concept, its use is widely accepted in the preferences literature, as it represents one of the most dynamic landscape layers to which people readily relate (Dramstad, Tveit, Fjellstad, \& Fry, 2006; Pinto Correia \& Carvalho Ribeiro, 2012).

In addition to the previous point, it is also important to acknowledge that one single land cover can be used in different ways. Thus it can be associated with multiple land uses. For example, land cover classes such as pastures can be used by farmers as a place for grazing their livestock. But it can also be used as horseback recreational activity illustrating that a single land cover may have contrasting land uses (Verburg, van de Steeg, Veldkamp, \& Willemen, 2009). There is thus the need to disentangle the links between land cover, land use and land function (Verburg et al., 2009). This is approached by considering land cover as distinguishable vegetation structures (grass, pine tree), while land use is the purposes made of land (residential, agriculture), and land function refers to the capacity of landscapes to provide various goods and services (de Groot, Wilson, \& Boumans, 2002).

Another difficulty facing this research is the need to tackle the unresolved problem of the scaledependency of both landscape preferences and spatial pattern analysis (Andersson, Ahrné, Pyykönen, \& Elmqvist, 2009; Bastian, Krönert, \& Lipský, 2006; Wu, 2004). While the term "scale" may refer to any one or combinations of several concepts, including grain, extent, lag (or spacing), and cartographic ratio, in this paper it refers only to "grain" (the spatial resolution of a map), and "extent" (the map size). This combination is termed "geographic scale" by Wu (2004). In terms of landscape planning and policy throughout Europe, scale issues are also very important as they need to be reconciled and integrated across four different levels of governance (EU, national, regional and local). The methodologies developed so far are mostly scale dependent where upscaling and downscaling are considered highly problematic (Wu, 2004). Consequently, contrasting methodological approaches which address different geographical scales are rarely linked (Massada \& Radeloff, 2010).

At the local scale, landscape preferences elicitation are mostly based on photo surveys where either a set of separate land covers or connected landscapes are shown to respondents. A good number of studies use digitally altered photos to increase the sharpness between contrasting objects or land covers (for a detailed description see Barroso, Pinto-Correia, Ramos, Surova, \& Menezes, 2012). The outcome of this type of approach is normally a classification of pre-defined and fixed single land cover classes or objects as more preferred/liked or less preferred/disliked. However, full landscapes are rarely composed as a single land cover so the gap is to explore the set of different possible land cover compositions specifically focusing on land cover patterns (a mix of individual land covers).

In order to overcome these issues, surveys have been carried out where the photos shown to respondents are not altered digitally, and both the exact coordinates of the location of the photos as well as the viewshed (an area or other element that is visible to the human eye from a fixed vantage point) are known (Habron, 1998). Thus a direct match between the photo and the real landscape can be made (for a more detailed description of this approach, see Dramstad et al., 2006). Yet two problems remain. First, although information rich, these types of approaches are almost impossible to upscale from the local (where the survey normally is conducted) to the regional scale (where most of planning procedures are usually carried out). The digitally altered photos lose their connection with the "real world landscapes". Although they are very effective for communicating contrasting preferences regarding predefined objects/land covers, it is very difficult to translate them back to a geographical location (Barroso et al., 2012). The alternative approach, in which the coordinates of the viewshed of the photos are known, still holds its spatial background. But this is also challenging when upscaled for regional planning purposes, as there are well known shortcomings because of scale dependencies associated with landscape indices and metrics (Uuemaa et al., 2009). Second, the previous approaches both assume that there are sharp boundaries between land covers characteristic of Northern and Central Europe. However, in the Mediterranean with more "fuzzy" landscape settings, these premises cannot be assumed (PintoCorreia et al., 2011). In the traditional extensive agro-forestry systems of the Mediterranean it is sometimes difficult to draw reliable boundaries across contrasting land covers (Barroso et al., 2012).

To overcome these methodological issues this research offers two innovative approaches. One is to go beyond the assessment of single land covers by focusing on land cover patterns (a composition of different land covers), using a non-spatial model (a block diagram by Michelin, Joliveau, \& Planchat, 2011) that is meaningful for respondents. The other innovation is to map the land cover pattern compositions preferred by different landscape users for contrasting activities (e.g. farming, hunting) into land cover pattern preference maps. This helps regional planning and policy making.

The overall goal of this work is to build and test the Landscape Preferences Spatial Framework (LPSF) for depicting onto land cover pattern maps the preferences of different landscape user groups in the fuzzy landscape settings of the Mediterranean. This approach makes it possible for preferences of user groups to be elicited in ways which are easy to understand, participatory friendly, and operational for planning.

\section{Study area and methods}

\subsection{Study area}

Alentejo is located in southern Portugal. Its administrative organization occupies a third of the area of the country $\left(31,551 \mathrm{~km}^{2}\right)$ comprising a set of 47 municipalities (Fig. 1). Within this geographical area, a diversified sample of landscape users was selected so as to capture the variety of societal demands occurring for Alentejo landscapes. Stemming from the results of previous studies dealing 


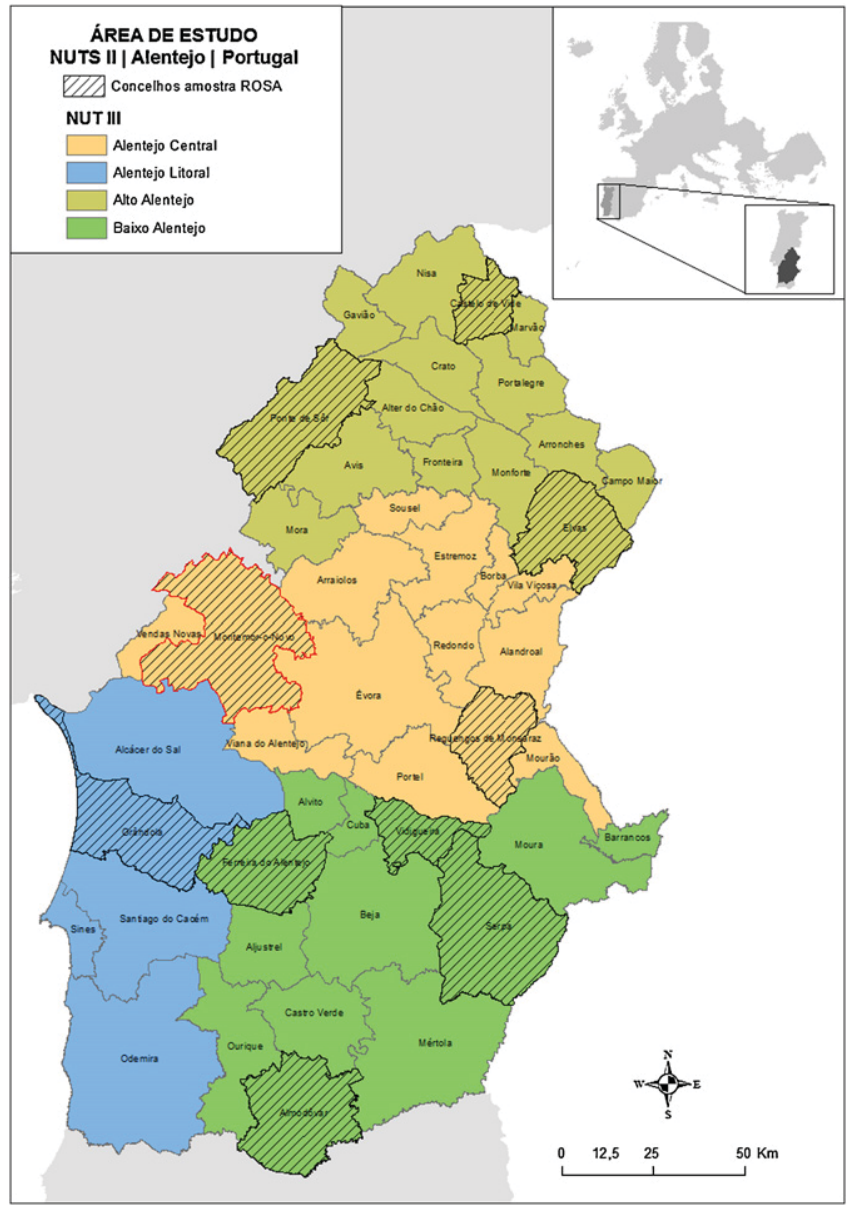

Fig. 1. Case study area location and administrative divides. (For interpretation of the references to color in text, the reader is referred to the web version of the article.)

with landscape preferences in the area (Pinto-Correia et al., 2011; Surova \& Pinto-Correia, 2008), five groups were selected: land managers, hunters, inhabitants, visitors, and tourists. (For a more detailed description of these landscape users see Pinto Correia \& Carvalho Ribeiro, 2012).

To survey across the whole region (NUTs II), a set of ten municipalities were selected according to three major criteria: (a) to cover different geographical divides of the Alentejo region, (b) to enjoy logistical support from trained local partners to conduct the survey in the municipalities selected, and (c) to ensure that in the set of ten selected municipalities the characteristic land cover types of the whole Alentejo region were studied. Fig. 1 shows both the geographical location of Alentejo in the European context, its four regional divides (shaded in different colours), the ten municipalities surveyed in this research (black lines) as well as the case study Montemor-o-Novo municipality (red line). Table 1 also shows that the selected sample of 10 municipalities contained contrasting land cover classes.

\subsection{Methods: data collection}

The main goal was to survey at least 200 respondents from each of the five user groups: or around 20 respondents from each user group in each of the 10 selected municipalities. In order to reach the 200 questionnaires with the sample specification described above, before conducting the survey, a meeting was held between the research team and each of the 10 selected local municipal planning officers to ensure that the research team was acquainted with the patterns of local users. The survey sampling started through the contacts given but developed a "snowball approach" to enlarge the sample. For data collection, individual interviews, using photographs as visual stimuli, were used.

\subsubsection{Photo-based questionnaire}

An important step in the research process concerned the development, testing and application of a photo-based questionnaire. The photos that were shown throughout the survey (Fig. 2) were manipulated in Photoshop, each showing a single land cover class as classified in the Corine Land Cover III level legend (Table 1), whose captions are sufficiently descriptive of the majority of the land cover classes in the study area. In this way the 3D landscape representation (block diagram) was associated with a standardized 2D cartographic representation (Fig. 2). In fact the Corine Land Cover (European Environment Agency http://www.eea.europa.eu/publications/COR0-landcover accessed 05.12.12), is part of the UE Programme, Corine Biotopes. This is intended to provide homogenous, consistent and standardized geographical information on landscapes (urban, rural-forestry, natural, and water), essential when preparing and implementing European Union land use planning policies.

This questionnaire assessed different aspects of the preferences between respondents and their surrounding landscapes. At the beginning of each questionnaire, the respondents were introduced to the purposes of the survey. Respondents were then asked to choose only one role from the set of five user groups offered: (1) inhabitant; (2) farmer; (3) hunter; (4) regular visitor; and (5) tourist. Even if the respondent fitted into several user groups, as for example a farmer also being a local inhabitant, he/she was asked to choose only one role, and to respond according to that role throughout the survey. Respondents were also asked several questions about their socio-economic and demographic backgrounds such as place of residence, age class, and socio-economic activity. A detailed description of the questionnaire can be provided on demand.

The key question was framed as follows: in order to have the preferred land cover pattern for the activity you previously chose (and the activity was again repeated) please place one of the 16 individual photos (Fig. 2, top) in each plot of (Fig. 2, bottom) in order to represent your preferred land cover pattern composition for the activity you selected. You can repeat the same photo in the different plots as many times you would like to in order to make your preferred land cover composition.

The respondents then placed photos in the bock diagram with their preferred distribution of land cover classes (land cover patterns) for the particular activity which they carried out in the area (Michelin et al., 2011; Pinto Correia \& Carvalho Ribeiro, 2012). As explained above the land covers represented in the photos of Fig. 2 have a correspondence to the Corine land cover classes (please see Table 1). In the Corine classifications, only class 242 represents a mosaic: all the other classes are homogeneous land covers. With this Landscape Preferences Spatial Framework the ways in which land cover patterns may be associated with contrasting land uses was explored.

\subsection{Methods: data analysis}

The major challenge was to bridge two well established methodological approaches in such a way that landscape preferences by landscape users and spatial pattern analysis methods could be integrated (Fig. 3) into a comprehensive Landscape Preferences Spatial Framework (LPSF). The methodological approaches involving the analysis of the data from the landscape preference survey (Section 2.3.1.) were associated with the spatial pattern analysis of the Corine land cover maps (Section 2.3.2). Fig. 3 summarizes the research steps involved as well as the different stages of the analysis. 